\title{
Discussion of Agglomeration Mechanisms between Hydrate Particles in Water in Oil Emulsions
}

\author{
E. Colombel', P. Gateau', L. Barré', F. Gruy² and T. Palermo' \\ 1 Institut français du pétrole, IFP, 1-4 avenue de Bois-Préau, 92852 Rueil-Malmaison Cedex - France \\ 2 École Nationale Supérieure des Mines, 158 cours Fauriel, 42023 Saint-Étienne - France \\ email: emilie.colombel@geoservices.com - patrick.gateau@ifp.fr - loic.barre@ifp.fr - fgruy@emse.fr - thierry.palermo@total.com
}

\begin{abstract}
Résumé - Discussion sur les mécanismes d'agglomération entre particules d'hydrate dans les émulsions eau dans huile - Le bouchage des conduites lors de la formation des hydrates de gaz dans les émulsions eau dans huile peut être appréhendé par l'augmentation de la fraction volumique effective de la suspension de particules d'hydrate. Cette augmentation est due à un processus d'agglomération qui se produit pendant la phase de formation des hydrates.

Deux mécanismes d'agglomération présentés dans la littérature sont discutés. Le premier est le mécanisme d'agglomération induit par contact pour lequel le processus de cristallisationagglomération est le résultat du contact entre une goutte d'eau et une particule d'hydrate. Le second est le mécanisme d'agglomération limité par le cisaillement pour lequel la compétition entre force hydrodynamique et force adhésive est considérée.

Il est proposé de réunir ces deux mécanismes dans un modèle unifié afin de prédire l'évolution de la viscosité de la suspension d'hydrate pendant la formation. Un tel modèle repose sur un modèle de bilan de population dans lequel le noyau d'agglomération est associé au mécanisme d'agglomération induit par contact et le noyau de fragmentation est associé au mécanisme d'agglomération limité par le cisaillement.
\end{abstract}

\footnotetext{
Abstract - Discussion of Agglomeration Mechanisms between Hydrate Particles in Water in Oil Emulsions - Line blockage due to gas hydrate formation in water/oil emulsions can be understood by considering the increase in the effective volume fraction $\varphi_{\text {eff }}$ of dispersed particles in the hydrate slurry. This increase is the result of an agglomeration process that takes place during hydrate formation.

Two mechanisms of agglomeration reported in the literature are discussed. The first one is the contact-induced agglomeration mechanism for which the crystallization-agglomeration process is described as the result of the contact between a water droplet and a hydrate particle. The second one is the shear-limited agglomeration mechanism for which the balance between hydrodynamic force and adhesive force is considered.

It is proposed to gather these two mechanisms in a unified model in order to predict the evolution of the viscosity of the slurry during hydrate formation. Such a model can be based on a Population Balance Model in which the agglomeration kernel is related to the contact-induced mechanism and the fragmentation kernel is related to the shear-limited mechanism.
} 


\section{INTRODUCTION}

The hazard of gas hydrate formation causing blockages in production lines remains today one of the main concerns to deepwater field developments. The present strategy of operators is commonly focused on the deployment of prevention methods that aim at producing outside the hydrate domain. This can mainly be achieved via pipeline insulation (for oil dominated systems) or thermodynamic chemical injection (for gas dominated systems).

Another strategy is to produce inside the hydrate domain by transporting the hydrate phase as a slurry of hydrate particles dispersed in the oil phase. It was first proposed about twenty years ago [1] and led to developments of AntiAgglomerant additives (AA), a family of the so-called Low Dosage Hydrate Inhibitors (LDHI). Investigations at lab scale [2] and pilot scale [3,4] up to field deployment under deepwater environment [5] demonstrated the applicability of this strategy. Even so, injection of such chemicals remains still marginal. Similarly, natural surfactants (asphaltenes, resins, acidic compounds, etc.) present in most of black oils were also considered as potential agents enabling hydrates to be transported as a slurry [6]. Operators have been envisaged to take advantage of such surfactant properties, particularly to ensure restarting after a long shutdown. Associated with subsea water separation, oil properties would also make viable the development of satellite fields connected to existing platforms via long tie-backs. Investigations of crude oils with respect to hydrate control have thus been conducted for numerous years [7-9]. Most of them show results on plugging or non-plugging occurrence in laboratory facilities or pilot loops and do not allow us to predict flow conditions inside the hydrate domain. In a first attempt [10], the concept of formation of hydrate fractal aggregates, derived from colloid science [11], was introduced. Later, a series of papers dealing with agglomeration mechanisms have been published [12-17].

In the following, mainly based on previous reported studies, we will discuss agglomeration mechanisms thought to be involved between hydrate particles in systems composed of water in crude oil emulsions. Note that, from a practical point of view, limitation to such systems is not restrictive. Indeed, most crude oils contain natural surfactants that promote formation of water in oil emulsions [18], at least up to water cut of $50 \%$.

It is expected that hydrate plug formation for oil dominated systems is mainly related to the evolution of bulk properties. That excludes blockage caused by deposit formation. Hydrate deposits are expected to form with gas or gas/condensate dominated systems. They also might form in oil when hydrate particles are subjected to temporarily flow in a section above the melting temperature, which is in favour of making "wet" hydrate particles.

Evolution of bulk properties can be formalized in terms of the evolution of the "effective volume fraction" of hydrate particles: $\varphi_{\text {eff }}$. During hydrate formation, hydrate crystals form at the water-oil interface, making a solid shell around water droplets. The system is therefore a dispersion that changes progressively from a water-in-oil emulsion to a hydrate-in-oil suspension. Rheological properties of hydrate suspensions have been presented and discussed in former papers $[10,12]$. If no agglomeration process takes place, we can consider that $\varphi_{\text {eff }}$ will roughly correspond to the water cut. On the other hand, agglomeration of primary hydrate particles will lead to an increase in $\varphi_{\text {eff }}$. Particles that result from an agglomeration process are generally large and porous. In this case, $\varphi_{\text {eff }}$ can be expressed as a function of the water cut $\varphi$ and the average radius ratio between agglomerates $(R)$ and water droplets $(a)$ according to the following equation: $\varphi_{e f f}=\varphi(R / a)^{3-D}$. For porous agglomerates, the fractal dimension $D$ is a number lower than 3. It is well accepted that, for perikinetic aggregation, it ranges from about 1.7 to 2.1 . Under shear conditions, it is generally reported that aggregates are more compact with a fractal dimension larger than 2 and up to 2.7 [10]. As an indication, for $D \approx 2$ we can see that $\varphi_{\text {eff }}$ would increase linearly with the average size of hydrate agglomerates.

The effective volume fraction can be considered as a relevant variable indicating limitation in transporting hydrate suspensions. Theoretically, the maximum volume fraction corresponds to the maximum packing fraction associated with a viscosity tending to infinity. For monodisperse spheres, it is around $60 \%$. However, above a lower value, the suspension does not behave as a liquid anymore but behaves as a paste or a visco-plastic solid, corresponding to a high risk situation with respect to plug formation. It is difficult to

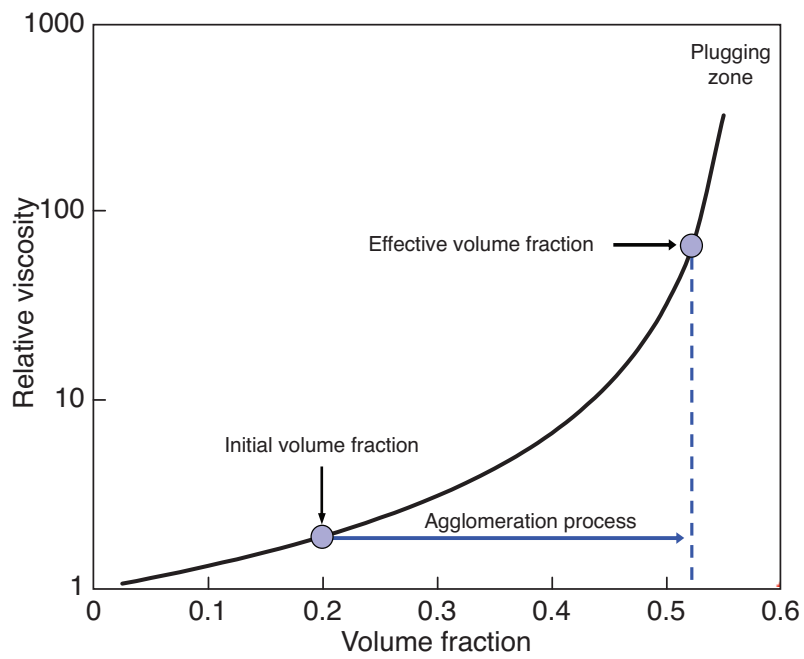

Figure 1

Typical evolution of the relative viscosity with the effective volume fraction. 
estimate precisely this critical threshold. In a first approximation, it can be set around 50\%. Figure 1 illustrates the typical evolution of the relative viscosity (apparent viscosity of the hydrate suspension divided by the oil viscosity) with the effective volume fraction. In this example, the agglomeration process makes $\varphi_{\text {eff }}$ evolving towards the plugging zone up to more than $50 \mathrm{vol} \%$.

In case of black oil systems, for moderate water cuts, the increase in the effective volume fraction is generally limited and only an increase in the pressure drop is observed $\left(D P_{\text {in/out }}\right.$ in Fig. 2). As soon as water droplets are transforming into hydrate particles (Conversion in Fig. 2), the pressure drop rises, reaches a maximum magnitude and then often stabilizes at a lower plateau value.

Basic mechanisms involved in hydrate agglomeration are not yet definitively established. As frequently reported by the hydrate community, hydrate plug formation is seldom observed once hydrate formation is completed and hydrate particles are well dispersed in the oil phase. On the other hand, the risk of plug formation mainly occurs during the hydrate formation phase. As a result of the expected hydrophilic character of hydrate surface, it was suggested that capillary forces may be responsible for the agglomeration process between hydrate particles $[19,10]$. Recently, particle-particle pulloff adherence forces were measured as a function of temperature in the ice/n-decane/ice and tetrahydrofuran (THF) hydrate/n-decane/THF hydrate systems using a micromechanical testing technique [13]. The observed forces and trends were explained by the capillary cohesion of rough surfaces, with the capillary bridging liquid being stabilized below its freezing point by the negative curvature of the bridging liquid/n-decane interface. Regarding the prediction of the hydrate slurry viscosity two different approaches have been reported in the literature. The first one can be referred to as a contact-induced agglomeration model [14-16]. In this model, the crystallisation-agglomeration process is described as the result of a contact mechanism between a water droplet and a hydrate particle. The size of hydrate aggregates mainly depends of a characteristic time of crystallization and of a characteristic time of agglomeration. The growth of hydrate particles stops when all the water droplets are crystallized. The second one can be referred as a shear-limited agglomeration model [17]. In this case, the size of aggregates mainly depends on the balance between the hydrodynamic force exerted on the aggregates and the adhesive force between primary particles inside the aggregates.

Below, we will mainly come back both on the contactinduced agglomeration and the shear limited agglomeration mechanisms. We will show that these two models are not opposite. On the contrary, a merge of these two approaches in a unified model should yield a consistent understanding of the agglomeration process during hydrate formation under flow conditions.

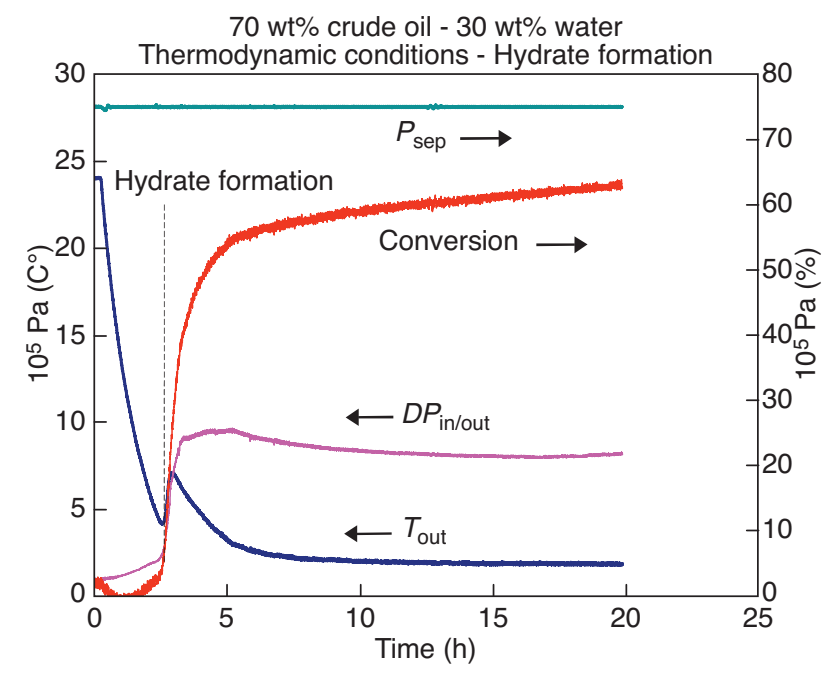

Figure 2

Hydrate formation under steady state multiphase flow for a crude oil system [9].

$T_{\text {out }}:$ temperature at the outlet of the line, $D P_{\text {in/out }}:$ pressure drop along the $140 \mathrm{~m}$ line, Conversion: percentage of water converted into hydrate, $P_{\text {sep }}$ : pressure at the outlet of the line.

\section{EVIDENCE OF THE CONTACT-INDUCED AGGLOMERATION MECHANISM}

Methane hydrate formation and agglomeration for different water in oil emulsions were investigated in a high pressure cell implemented in a Differential Scanning Calorimeter (microDSCVII from SETARAM) [15].

Emulsions were prepared by mixing $30 \mathrm{wt} \%$ of deionised water with $70 \mathrm{wt} \%$ of crude oil. Three different crude oils, named A, B and C were studied. Observation by optical microscopy showed similar size distribution of water droplets with radii not exceeding $10 \mu \mathrm{m}$.

Heat flow was recorded for successive runs of formation dissociation. Hydrate formation took place under isothermal conditions at a working temperature $T^{*}$ of $263 \mathrm{~K}$ and a pressure of $13.5 \mathrm{MPa}$. Once hydrate formation was completely achieved, the emulsion was warmed up to $298 \mathrm{~K}$, in order to dissociate hydrates. Then, the system was cooled down again for the following run. The rate of cooling and warming was fixed at $1 \mathrm{~K} / \mathrm{min}$. Following this procedure, no ice formation was observed (no peak at $T \approx 272 \mathrm{~K}$ at $P=13.5 \mathrm{MPa}$ ). Analysis of the shape of exothermic peak recorded under isotherm conditions allowed the authors to discuss the kinetic of hydrate formation while the quantity of hydrate formed was determined by measuring the area of the endothermic peak during dissociation.

First, the change in the quantity of hydrate formed during successive runs was reported. This variation was expected to be related to the agglomeration process between hydrate 
particles that occurs during hydrate formation. The relation between the change in the quantity of hydrate and the agglomeration process was based on the following assumptions:

- The quantity of hydrate depends on the specific surface area of the water-oil interface. Let us define a primary particle as a particle formed from the crystallisation of only one water droplet. It is supposed to be composed of a liquid core and a hydrate shell whose thickness does not strongly depend of the size of the water droplet (hydrate shell model).

- If hydrate particles are formed from the agglomeration of several primary hydrate particles, hydrate dissociation will result in the formation of larger water droplets and, thus, will lead to a decrease of the specific surface area. Indeed, for a given total volume of water $V_{t o t}$, the total surface area of water droplets $A_{t o t}$ is:

$$
A_{t o t}=3 \frac{V_{t o t}}{a}, \text { with } a \text { the radius of the droplets. }
$$

Regarding the second assumption, it should be noted that the authors neglected the possible breaking of the emulsion during dissociation due to the coalescence between two droplets formed from the melting of two separated hydrate particles. The possibility of such an effect was recently highlighted by others also utilizing the DSC technique [20].

Effect of the specific surface area is clearly highlighted in Figure 3. Tests were carried out for two systems composed of $30 \mathrm{wt} \%$ of water and $70 \mathrm{wt} \%$ of crude C. In the first case, the water phase was dispersed in the oil phase as an emulsion. In the second case, the water phase was in contact with the oil phase as free water. Thermograms show that the magnitude

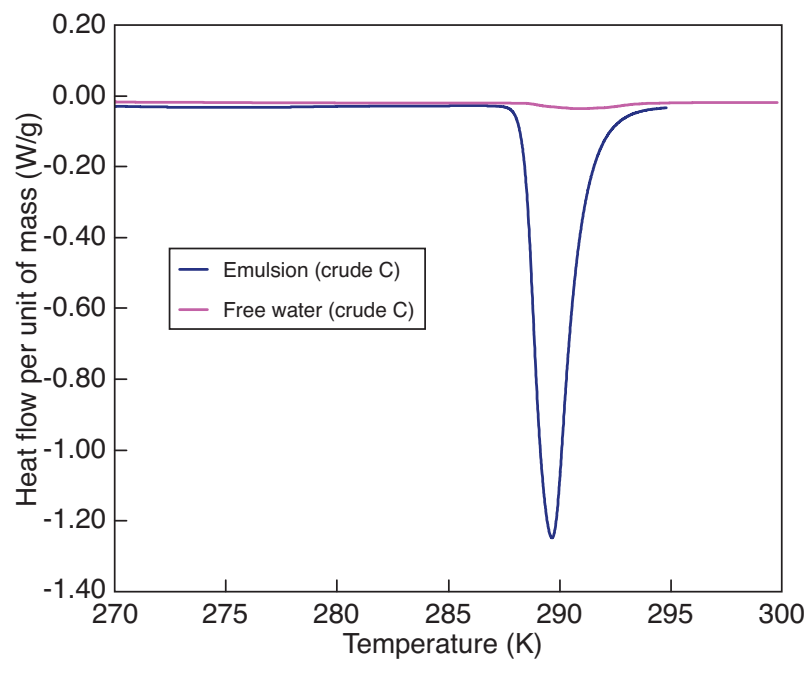

Figure 3

DSC thermograms of methane hydrate dissociation for 30 wt $\%$ water / $70 \mathrm{wt} \%$ crude C systems: emulsion and free water (adapted from [15]). of the peak of dissociation is strongly affected depending on the dispersion state of the water phase.

Endothermic peaks of dissociation corresponding to two or three successive runs, are given in Figure 4 for each crude oil emulsions. Heats of dissociation for the first run are nearly identical for each system (without any peak related to ice formation). It means that the same amount of hydrate has been formed during the first isotherm, which is in agreement with size similarity of water droplets whatever the crude oil. On the other hand, it can be seen that the crude oils exhibit different behaviours regarding the variation of the quantity of hydrate formed from the first run of formation-dissociation and the following ones. For crude A, the successive peaks of dissociation are superimposed and there is no change in magnitude of the heat of dissociation. The amount of hydrate formed remains roughly the same during the three runs. In that case, the size of water droplets is not modified. On the contrary, there is a strong reduction of this quantity for emulsions prepared with crude B and crude C. This diminution reveals a decrease of the specific surface area and then an enlargement of the water droplets diameter between the successive runs. These results show different levels of agglomeration depending on the crude oil. However, in the work reported in [15], hydrate formation occurred in the DSC (for practical reasons) at a much lower temperature than in field conditions. Moreover, hydrate formation occurs at rest in the DSC. Since agglomeration is expected to be strongly dependant on conditions enabling droplets to come into contact (crude oil viscosity for example), this level of agglomeration thus may not be directly related to the "antiagglomerant" properties of the crude under real conditions.

A relationship between the kinetic of hydrate formation and the level of agglomeration was highlighted by comparing the exothermic peaks recorded during the first run isotherm (Fig. 5). The most significant fact is the difference in rate of formation: the higher the level of agglomeration, the higher the rate of formation.

The coupling fast-crystallization/strong-agglomeration for crude $\mathrm{C}$ and, less significantly for crude $\mathrm{B}$, was interpreted as the result of the propagation of the crystallization through neighbouring droplets. The link between kinetics and agglomeration suggests the following scenario: a hydrate aggregate composed of $i+1$ primary hydrate particles is obtained from the crystallization of a droplet contacting an aggregate composed of $i$ primary particles. If two droplets crystallize separately, the resulting hydrate particles cannot stick together.

\section{EVIDENCE OF THE SHEAR-LIMITED AGGLOMERATION MECHANISM}

Such a contact-induced agglomeration mechanism, as described above, was considered in two similar models, 

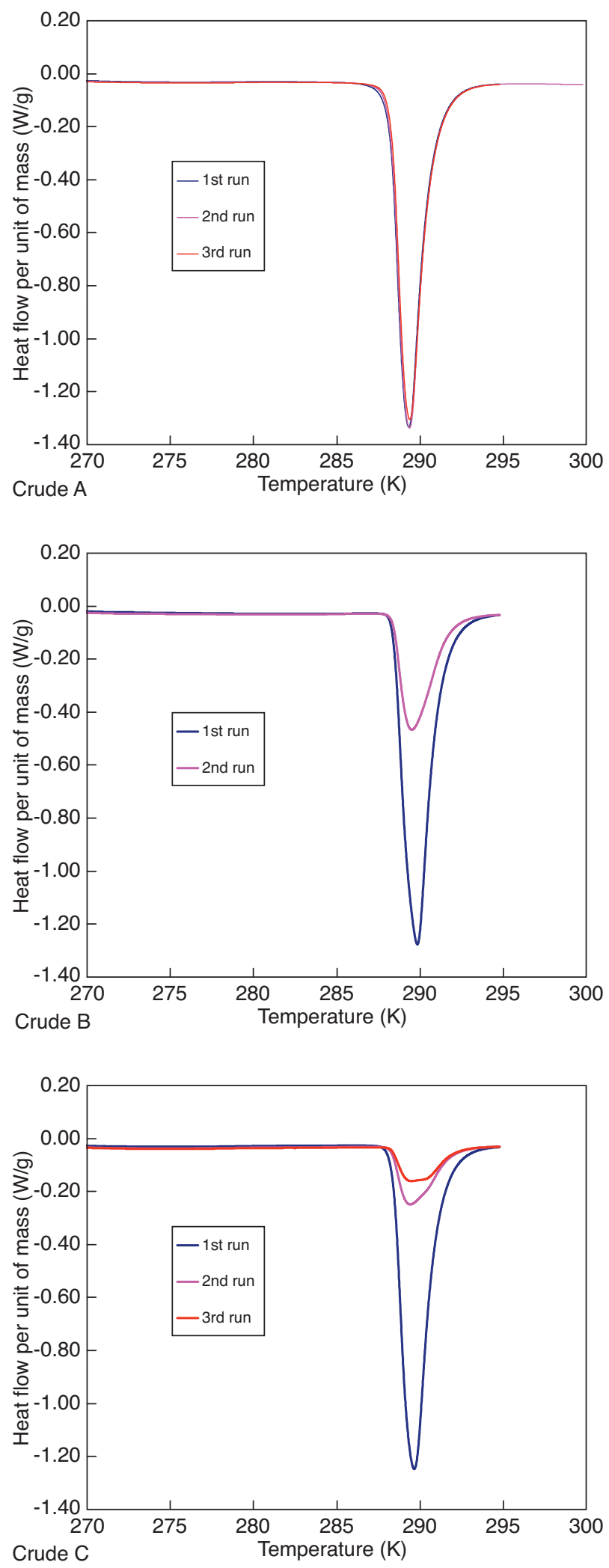

Figure 4

DSC thermograms of methane hydrate dissociation for emulsions with crude $\mathrm{A}$, crude $\mathrm{B}$ and crude $\mathrm{C}$ for successive runs of formation-dissociation (adapted from [15]).

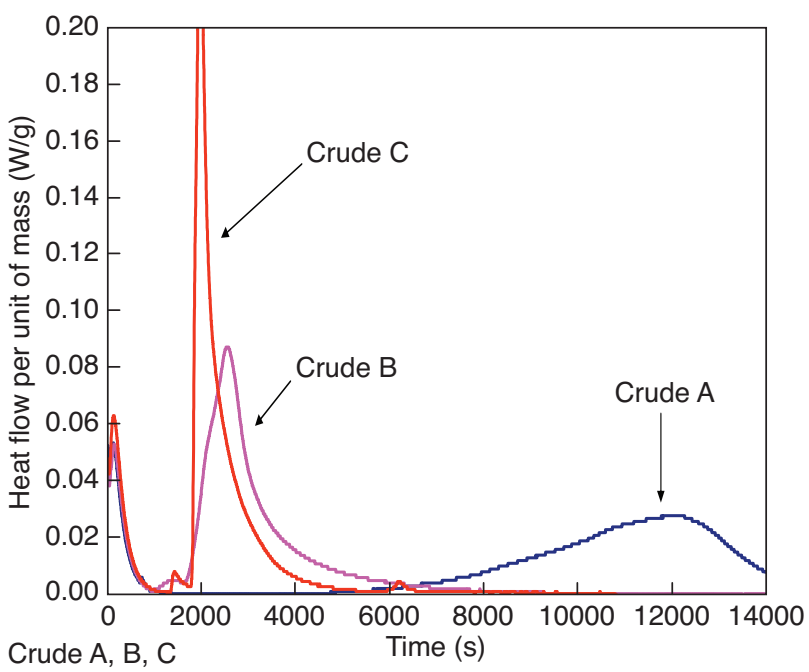

Figure 5

DSC thermograms of methane hydrate formation with crude $\mathrm{A}, \mathrm{B}$ and $\mathrm{C}$ during the first run (adapted from [15]).

which attempted to describe the viscosity rise during hydrate formation $[14,16]$. In these two approaches, based on Population Balance Models, no breakage kernel was included and the process of agglomeration stopped once all the water droplets were transformed into hydrate particles.

More recent attempts to generalize the approach presented by [16] failed in predicting the final viscosity of hydrate slurries for a wider range of conditions in terms of water cut and flow rate. On the other hand, a good agreement has been obtained by considering an average size of aggregates controlled by the shear rate [17].

In case of a shear-limited agglomeration process, the final size of hydrate particles is related to the shear stress $\tau$ as:

$$
\frac{R}{a}=\left(\frac{\tau_{0}}{\tau}\right)^{m}
$$

where $R$ is the aggregate radius, $a$ the primary particle radius ( $\approx$ droplet radius), $\mu$ the apparent viscosity of the suspension, $\tau_{0}$ the critical shear stress below which aggregates can form and $m$ an exponent which depends on the breakage mechanism. It is generally reported in the range $0.3-0.5$ in the literature [21]. The critical shear stress is related to the force of adhesion $F$ between particles as:

$\tau_{0} \propto \frac{F}{a^{2}}=\frac{\sigma}{a}$ where $\sigma=\frac{F}{a}$ is the energy of adhesion per area unit and depends only on the physico-chemical properties of the system.

The effective volume fraction $\varphi_{\text {eff }}$ scales with the actual volume fraction $\varphi(\approx$ water cut $)$ as:

$$
\varphi_{\text {eff }}=\left(\frac{R}{a}\right)^{3-D} \varphi=\left(\frac{\tau_{0}}{\tau}\right)^{(3-D) m} \varphi
$$




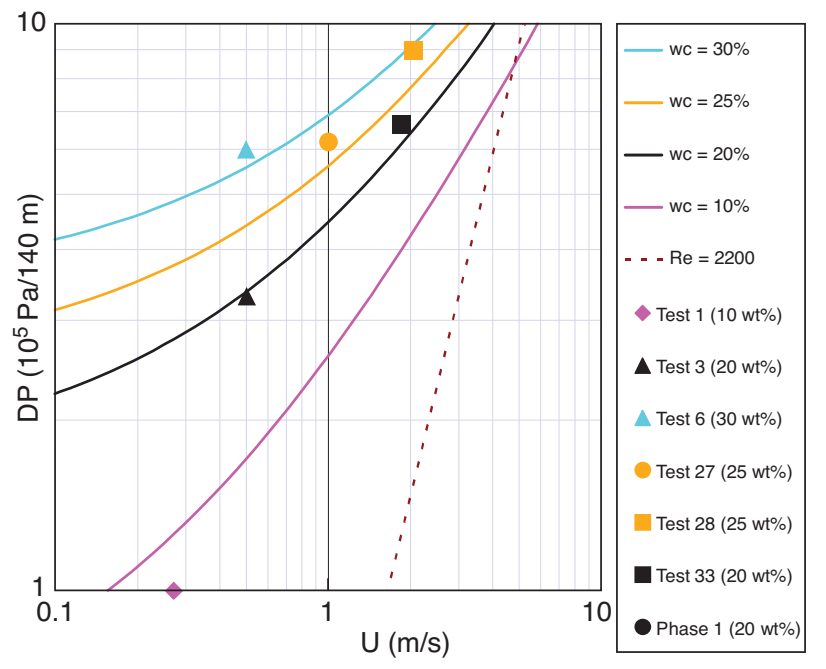

Figure 6

Comparison between experimental data and predictions for a $5 \mathrm{~cm}$ diameter pipe (from [17]). Continuous lines: calculated according to the relation $D P=32 \mu\left(\varphi_{\text {eff }}\right) U L / d^{2}$.

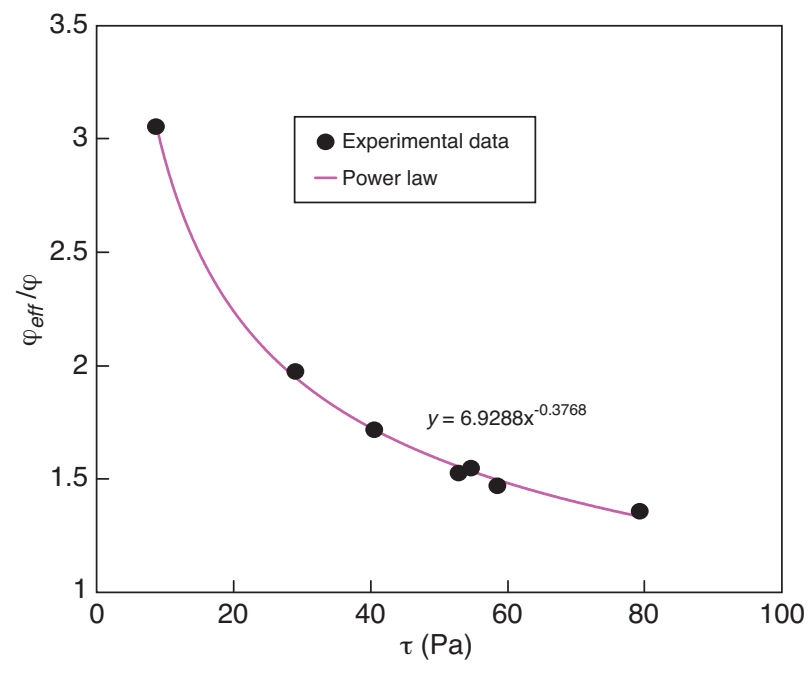

Figure 7

Representation of $\varphi_{e f f} / \varphi$ as a function of $\tau$. Experimental data adapted from [17]. Comparison with Equation (3). where $D$ is an exponent (fractal dimension) expected to be of the order of 2.

Equation (2) can be re-written as:

$$
\frac{\varphi_{e f f}(\mu)}{\varphi}=\tau_{0}{ }^{X}(\tau)^{-X} \text { with } X=(3-D) m
$$

Finally, the viscosity of the suspension $\mu$ can be related to $\varphi_{\text {eff }}$ by an expression of the form:

$$
\mu=\mu_{0} \frac{1-\varphi_{\text {eff }}}{\left(1-\frac{\varphi_{e f f}}{\varphi_{M}}\right)^{2}}
$$

with $\mu_{0}$ the oil viscosity and $\varphi_{M}$ the maximum packing: $\varphi_{M}=4 / 7$.

Experimental data obtained in a pilot loop were initially reported in [17] under the form of the Pressure Drop $D P$ as a function of the velocity $U$ (Fig. 6). The pressure drop was recorded at the plateau value (Fig. 2) under laminar liquid flow conditions in a $L=140 \mathrm{~m}$ long and $d=5 \mathrm{~cm}$ diameter line.

In order to point out the scaling dependency of $\varphi_{\text {eff }}$ with $\tau$ according to Equation (3), the same data are reported here under the form of $\varphi_{\text {eff }} / \varphi$ as a function of $\tau$ (Fig. 7). It should be noted that data correspond to different water cuts $(10,20$, $25,30 \mathrm{wt} \%$ ) and different velocities (from $0.25 \mathrm{~m} / \mathrm{s}$ to $2 \mathrm{~m} / \mathrm{s}$ ).

The oil can therefore be well characterized with respect to the final state of hydrate agglomeration by the determination of the two physical parameters $\tau_{0}$ and $X$. In the example reported in Figure 7, we have $X=0.37$, which is consistent with a value of the fractal dimension $D$ around 2 and of the exponent $m$ in the range $0.3-0.5$. We can deduce the critical shear stress $\tau_{0}=6.9^{1 / X} \approx 170 \mathrm{~Pa}$. Taking a radius of water droplets around $10 \mu \mathrm{m}$, it corresponds to a force $F$ of the order of $2 \mathrm{nN}$ and a surface energy $\sigma$ of the order of $2 \mathrm{mN} / \mathrm{m}$.

\section{TOWARDS A UNIFIED MODEL OF AGGLOMERATION}

The two mechanisms presented above have been shown to be involved in the hydrate agglomeration process. However, while the contact-induced agglomeration model is not able to correctly predict the final viscosity of the hydrate slurry contrary to the shear-limited agglomeration model, this last one does not allow us to predict the evolution of the viscosity during hydrate formation.

A complete description of the agglomeration process should therefore gather these two mechanisms. Such an approach was recently proposed [22], based on the development of a Population Balance Model. It should be noted that such an approach (population balance including both aggregation and breakage kernels) has widely been reported in the literature to describe aggregated suspensions (see for example [23]). To our knowledge, it has never been applied to hydrate suspensions. A reason may be that the agglomeration mechanism for hydrate suspensions is not described as a reversible aggregation process between solid particles but as the result of the contact between a water droplet and a hydrate particle. In this last case, the agglomeration process is stopped once all the water droplets are consumed and the final mean size of hydrate particles is mainly controlled by the breakage mechanism. For a 
reversible aggregation mechanism, the final mean size of aggregates is controlled by the balance of aggregation rate and breakage rate.

The evolution of the system is based on the pseudochemical reactions:

$$
\left\{\begin{array}{l}
(0) \stackrel{1 / \theta_{K}}{\longrightarrow}(1) \\
(i)+(0) \stackrel{K_{i}^{A}}{\longrightarrow}(i+1) \\
(i+1) \stackrel{K_{i+1}^{F}}{\longrightarrow}(i)+(1)
\end{array}\right.
$$

According to the contact-induced agglomeration mechanism, a water droplet (0) can crystallize either individually to form a hydrate particle (1) or by contacting a hydrate aggregate $(i)$ to form an aggregate $(i+1)$. For the aggregate breakage process, two mechanisms can be considered: particle erosion (erosion of one primary particle at a time) or floc erosion (aggregate breaking up to pieces of different size) [24]. There is no clear evidence of the occurrence of a mechanism against the other one. For simplicity reasons, only the particle erosion mechanism has been arbitrary retained.

The evolution with time $t$ of the system is thus given by:

$$
\left\{\begin{array}{l}
\frac{d N_{1}}{d t}=\frac{1}{\theta_{K}} N_{0}-K_{1}^{A} N_{0} N_{1}+2 K_{2}^{F} N_{2}+\sum_{i>2} K_{i}^{F} N_{i} \\
\frac{d N_{i}}{d t}=K_{i-1}^{A} N_{0} N_{i-1}-K_{i}^{A} N_{0} N_{i}+K_{i+1}^{F} N_{i+1}-K_{i}^{F} N_{i} \\
N_{0}=1-\sum_{i \geq 1} i N_{i}
\end{array}\right.
$$

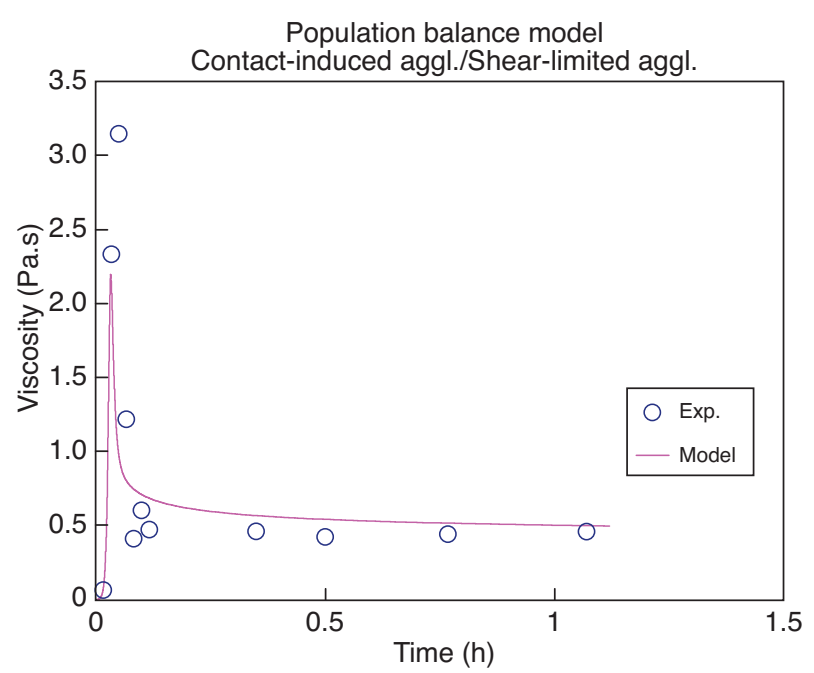

Figure 8

Evolution of the viscosity for trichlorofluoromethane hydrate formation in a water/oil emulsion (water cut of $33.6 \mathrm{vol} \%$ and shear rate of $\left.500 \mathrm{~s}^{-1}\right)$.

Model parameters: $\tau_{1}=20000 \mathrm{~Pa}, D=2.4, \theta_{A}=0.001 \mathrm{~h}$, $\theta_{K}=0.7 \mathrm{~h}$. where $N_{0}$ and $N_{i}$ are the number concentrations of water droplets and of aggregates composed of $i$ primary particles, respectively. $\theta_{K}$ is the characteristic time of crystallization, $K_{i}^{A}$ the aggregation kernel and $K_{i}^{F}$ the breakage kernel. $\theta_{K}$ and $K_{i}^{A}$ refer to the contact-induced agglomeration mechanism while $K_{i}^{F}$ refers to the shear-limited agglomeration mechanism.

In a first attempt, $K_{i}^{A}$ has been expressed as: $K_{i}^{A}=\frac{1}{\theta_{A}}$ where $\theta_{A}$ is a constant characteristic time of agglomeration, non dependent of the size of aggregates [25, 26]. The breakage terms of Equation (6) correspond to a particleerosion mechanism with $K_{i}^{F}$ expressed as:

$$
K_{i}^{F}=\dot{\gamma} \exp \left(-\frac{i^{\frac{D-3}{D}} \tau_{1}}{\mu \dot{\gamma}}\right)
$$

where $\tau_{1}$ is related to a cohesive pressure and $\dot{\gamma}$ the shear rate [27].

Finally, the evolution of the apparent viscosity $\mu$ of the system is calculated according to Equation (4) for which the effective volume fraction $\varphi_{\text {eff }}$ is determined from:

$$
\varphi_{e f f}(t)=\varphi\left(N_{0}(t)+\sum_{i \geq 1} i^{3 / D} N_{i}(t)\right)
$$

As an example, a comparison with experimental data [22] is reported Figure 8. Viscosity was recorded in a rheometer equipped with a "helix-type" agitator. Hydrate agglomeration was investigated in case of trichlorofluoromethane hydrate formation in water/oil emulsions. The oil phase was composed of toluene, trichlorofluoromethane and asphaltenes. In this example (water cut of $33.6 \mathrm{vol} \%$ and shear rate of $500 \mathrm{~s}^{-1}$ ), a high peak of viscosity followed by a plateau is observed. The model enables the general trend in the evolution of the viscosity to be correctly represented.

Beyond possible improvements, the capability to make this unified model fully predictive will need a better understanding of the dependence of the model parameters upon flow and thermal conditions. Besides, as crude oils exhibit different properties in terms of kinetics and hydrate agglomeration tendency, a minimum of experiments should be still required.

\section{CONCLUSION}

Line blockage due to hydrate formation for W/O emulsions can be understood by considering the increase in the effective volume fraction $\varphi_{\text {eff }}$ of the hydrate slurry. This increase is the result of an agglomeration process that takes place during hydrate formation.

Two mechanisms of agglomeration reported in the literature have been discussed. The first one is the contactinduced agglomeration mechanism for which the crystallization-agglomeration process is described as the 
result of the contact between a water droplet and a hydrate particle. The second one is the shear-limited agglomeration mechanism for which the balance between hydrodynamic force and adhesive force is considered.

It is proposed to gather these two mechanisms in a unified model in order to predict the evolution of the viscosity of the slurry during hydrate formation. Such a model can be based on a Population Balance Model in which the agglomeration kernel is related to the contact-induced mechanism and the breakage kernel is related to the shear-limited mechanism. This model is not presented here as a definitive one but rather as a possible new approach to help us in a better understanding of hydrate agglomeration during hydrate formation. Particularly, improvements in the breakage kernel should be expected.

\section{REFERENCES}

1 Sugier A., Bourgmayer P., Behar E., Freund E. (1990) Method of Transporting a hydrate Forming Fluid, US Patent 4,915,176.

2 Behar E., Delion A.S., Sugier A., Thomas M. (1994) Plugging control of production facilities by hydrates, Ann. N.Y. Acad. Sci. 715.

3 Palermo T., Sinquin A., Dhulesia H., Fourest J.M. (1997) Pilot loop tests of new additives preventing hydrate plugs formation, Multiphase'97, 7th International Conference on Multiphase, Cannes, 1997, pp. 133-147.

4 Palermo T., Maurel P. (1999) Investigation of hydrates formation and hydrates transportation with and without dispersant additives under multiphase flow conditions, Multiphase'99, 9th International Conference on Multiphase, Cannes, 1999, pp. 567-582.

5 Mehta A.P., Herbert P.B., Cadena E.R., Weatherman J.P. (2002) Fulfilling the Promise of Low Dosage Hydrate Inhibitors: Journey from Academic Curiosity to Successful Field Implementation, OTC 14057, Houston, Texas, 6-9 May 2002.

6 Palermo T., Mussumeci A., Leporcher E. (2004) Could Hydrate Plugging Be Avoided Because of Surfactant Properties of the Crude and Appropriate Flow Conditions? OTC 16681, Houston, Texas, 3-6 May 2004.

7 Nygaard N.F. (1989) Transportability of Hydrates in Multiphase Systems, Proceedings of the 4th International Conference on Multi-Phase Flow, Nice, June, 1989.

8 Maurel P., Palermo T., Hurtevent C., Peytavy J.L. (2002) Shutdown/Restart tests with an acidic crude under hydrate formation conditions for a deepwater development, Proceedings of the 13th International Oil Field Chemistry Symposium, Geilo, Norway, 17-20 March 2002.

9 Palermo T., Camargo R., Maurel P., Peytavy J.L. (2003) Shutdown/Restart pilot loop tests with an asphaltenic crude under hydrate formation conditions, Multiphase 03, 11th International Conference on Multiphase 03, San Remo, pp. 219-237.

10 Camargo R., Palermo T. (2002) Rheological properties of hydrate suspensions in an asphaltenic crude oil, Proceedings of the 4th International Conference on Gas Hydrates, 19-23 May 2002, Yokohama Symposia, Yokohama, Japan.
11 Mills P. (1989) Non-Newtonian behaviour of flocculated suspensions, J. Phys. Lett. 46, L301-L309.

12 Sinquin A., Palermo T., Peysson Y. (2004) Rheological and flow properties of gas hydrate suspensions, Oil Gas Sci.Technol. 59, 1, 41-57.

13 Yang S., Kleehammer D.M., Huo Z., Sloan E.D., Miller K.T. (2004) Temperature dependence of particle-particle adherance forces in ice and clathrate hydrates, J. Colloid Interf. Sci. 277, 335-341.

14 Fidel-Dufour A., Gruy F., Herri J.M. (2005) Rheology of methane hydrate slurries during their crystallisation in a water in dodecane emulsion under flowing, Chem. Eng. Sci. 61, 505-515.

15 Palermo T., Borregales M., Arla D., Dalmazzone C., Rousseau L. (2005) Study of the agglomeration between hydrate particles in oil using Differential Scanning Calorimetry (DSC), Proceedings of the Fifth International Conference on Gas Hydrates, 12-16 June 2005, Trondheim, Norway.

16 Palermo T., Fidel-Dufour A., Maurel P., Peytavy J.L., Hurtevent C. (2005) Model of hydrates agglomeration - Application to hydrates formation in an acidic crude oil, BHR Group 2005 Multiphase Technology, Barcelone.

17 Pauchard V., Darbouret M., Palermo T., Peytavy J.L. (2007) Gas Hydrate Slurry Flow in a Black Oil. Prediction of Gas Hydrate Particles Agglomeration and Linear Pressure Drop, Proceedings of 13th International Conference of Multiphase Production Technology, Edinburgh, UK, pp. 343-355.

18 Aske N., Kallevik H., Sjöblom J. (2002) Water-in-crude oil emulsion stability studied by electrical field measurements. Correlation to physico-chemical parameters and near-infrared spectroscopy, J. Petrol. Sci.Eng. 36, 1-17.

19 Austvik T., Xiaoyun L., Gjertsen L.H. (2000) Hydrate plug properties: Formation and removal of plugs, Proceedings of the 3rd International Conference on Gas Hydrates, Salt Lake City, Utah, USA, Holder G.D., Bishnoi P.R. (eds), Ann. N.Y. Acad. Sci. 912, 294-303.

20 Lachance J.W., Sloan E.D., Koh C.A. (2008) Effect of hydrate formation/dissociation on emulsion stability using DSC and visual techniques, Chem. Eng. Sci. 63, 3942-3947.

21 Potanin A. (1991) On the mechanism of aggregation in the shear flow of suspensions, J. Colloid Interf. Sci. 145, 1, 140-157.

22 Colombel E. (2008) Cristallisation et agglomération de particules d'hydrate de fréon dans une émulsion eau dans huile : Étude expérimentale et modélisation, Thèse de l'École Nationale Supérieure des Mines de Saint-Étienne.

23 Selomulya C., Bushell G., Amal R., Waite T.D. (2003) Understanding the role of restructuring in flocculation: The application of a population balance model, Chem. Eng. Sci. 58, 327-338.

24 Mühle K. (1993) Floc stability in laminar and turbulent flow, in Coagulation and Flocculation: Theory and Applications, Dobias B. (ed.), Surfactant Science Series, Vol. 47, Chap. 8.

25 Mumtaz H.S., Hounslow M.J., Seaton N.A., Paterson W.R. (1997) T. I. Chem. E75, A, 152.

26 Ilievski D., White E.T. (1994) Chem. Eng. Sci.49, 3227.

27 Ayazi Shamlou P., Stavrinides S., Titchener-Hooker N., Hoare M. (1994) Chem. Eng. Sci. 49, 2647.

Final manuscript received in May 2009 Published online in October 2009

\section{Copyright (C) 2009 Institut français du pétrole}

Permission to make digital or hard copies of part or all of this work for personal or classroom use is granted without fee provided that copies are not made or distributed for profit or commercial advantage and that copies bear this notice and the full citation on the first page. Copyrights for components of this work owned by others than IFP must be honored. Abstracting with credit is permitted. To copy otherwise, to republish, to post on servers, or to redistribute to lists, requires prior specific permission and/or a fee: Request permission from Documentation, Institut français du pétrole, fax. +33147527078 , or revueogst@ifp.fr. 